\title{
Mídias Digitais de Comunicação - Aprendizagem de Matemática a distância potencializada pela interação entre alunos e professores
}

Fabiana Fattore Serres

Marcus Vinicius de Azevedo Basso

\{fabiana.serres,mbasso\}@ufrgs.br

Instituto de Matemática - Universidade Federal do Rio Grande do Sul (UFRGS)

Porto Alegre - RS - Brasil

\section{Resumo}

No presente artigo apresentamos uma investigação de possíveis contribuições do uso de mídias digitais de comunicação na aprendizagem de matemática e descrevemos a dinâmica do trabalho desenvolvido com estudantes das séries finais do ensino fundamental do Colégio de Aplicação da Universidade Federal do Rio Grande do Sul (CAp-UFRGS). Destacamos os resultados parciais da análise de dados obtidos a partir dos registros dos estudantes e professores apontando a importância do exercício de produção textual por parte dos estudantes, bem como o uso das mídias digitais como potencializadores da interação e cooperação entre estudantes e professores e possíveis impactos na aprendizagem de matemática.

Palavras-chave: cooperação, mídias digitais, aprendizagem, matemática, interação.

\section{Digital Media Communications - Distance Learning Mathematics enhanced by interaction between students and teachers}

Abstract

In the present article we present an investigation of possible contributions from the use of digital medias of comunication in matemathical learning and we describe the work dinamics developed with students of the late years of elementary school from Colégio de Aplicação da Universidade Federal do Rio Grande do Sul (CAp-UFRGS). We salient the partial results from the analysis of the data gained from the students and teachers registers indicating the importance of textual production exercises, as well as the use of digital medias as empowerment of interaction and cooperation between students and teachers and possible impacts on mathematical learning.

Keywords: cooperation, digital medias, learning, mathematics, interaction.

\section{Introdução - o contexto de trabalho}

O Colégio de Aplicação (CAp-UFRGS), como parte da Universidade Federal do Rio Grande do Sul, tem o compromisso de dinamizar, atualizar, construir o conhecimento no que se refere ao Ensino Fundamental e Médio. Tendo como referência um ensino que compreende a interação professor-aluno como base, numa perspectiva dinâmica, procura desenvolver uma pedagogia a partir da análise de problemas, buscando formas democráticas de interação social.

Mesmo com esta proposta de interação, sentimos que salas de aula com 30 ou 40 alunos dificultam ao professor oferecer um atendimento personalizado qualificado, bem como acompanhar a evolução de cada estudante. Buscando uma solução para este impasse, desenvolvemos um trabalho no ano de 2009 com aproximadamente 250 alunos das séries finais do ensino fundamental. A idéia era intensificar a interação entre os alunos e professores e possibilitar o atendimento individualizado em momentos extraclasse. Nesse contexto, como parte da disciplina de Matemática, os alunos e professores 
construíram diários virtuais contendo atividades e reflexões envolvendo os conteúdos trabalhados em sala de aula.

O desenvolvimento deste trabalho consistiu em uma atividade semanal na qual os estudantes publicavam a solução do problema proposto e suas reflexões no seu diário virtual. Procuramos selecionar atividades que não possuíssem uma resposta única e imediata e que favorecessem a descrição do processo de solução mais do que apresentar apenas os resultados, pois nosso objetivo é que os estudantes reflitam sobre seus pensamentos e raciocínios matemáticos.

Como ambiente virtual de registro escolhemos os pbworks como ferramenta para desenvolver este trabalho. Pbworks são sites na web que permitem o trabalho colaborativo. São fáceis de usar permitindo uma edição rápida direto em um navegador de internet como se fosse um simples editor de texto. Deste modo qualquer um pode acrescentar, alterar ou apagar o conteúdo, ainda que este conteúdo não seja de sua autoria. Os pbworks permitem interação e colaboração entre professor-aluno e possuem histórico de modificações que permite ao professor avaliar a evolução dos registros dos alunos.

Com esta idéia e esta ferramenta poderíamos criar um espaço social de comunicação e de trabalho em grupo. Um espaço que permitisse ao estudante aprender a aprender, sendo co-responsável pelo próprio percurso de formação, com ênfase na aprendizagem de conceitos de matemática.

\section{Desenvolvimento e discussão dos resultados}

Dentre as atividades desenvolvidas no decorrer deste trabalho destacamos abaixo trechos, bem como a análise destes, retirados dos pbworks de alguns alunos.

\section{Figuras valiosas}

Sabendo que as figuras têm cada uma um valor,

\begin{tabular}{|c|c|}
\hline Figura & Valor \\
\hline Triângulo menor & 15 pontos \\
\hline Tiângulo maior & 30 pontos \\
\hline Quadrado menor & 12 pontos \\
\hline Quadrado maior & 24 pontos \\
\hline Círculo menor & 10 pontos \\
\hline Círculo maior & 20 pontos \\
\hline
\end{tabular}

Júlia fez uma composição usando só triângulos grandes e pequenos (no total 7 triângulos). Ela observou a tabela e calculou que sua composição valia 162 pontos.

É possível ela ter obtido esse resultado? Por quê? De que maneira ela poderia obter esse resultado?

R: É impossível a Júlia conseguir fazer uma composição usando só triângulos grandes e pequenos e ter 162 pontos. Para ela conseguir fazer essa composição com 7 triângulos e formar ao total 162 pontos ela tem que acrescentar um quadrado pequeno.

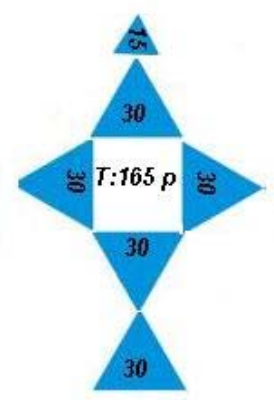

Obs: Passa 162

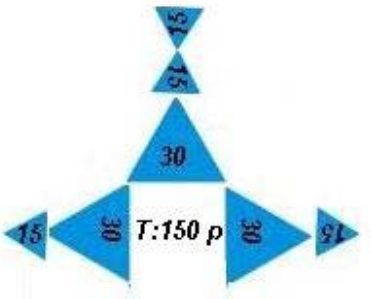

Obs: Inferior a 162

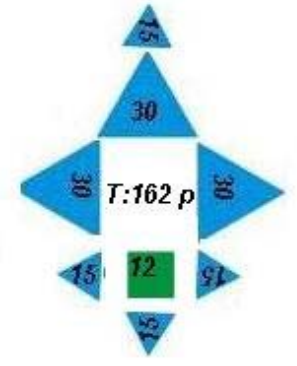

Obs: Exatamente 162 
Professora F: Muito bom aluno A, isso mesmo, eu fiquei pensando, e só com triângulos pequenos e grandes, dá pra somar uma quantia que termine em 2 , qualquer uma que tu quiseres? by profa $\mathrm{P}$

Aluno A: Professora F eu fiz dois exemplos como pede o exercício e um deles como a senhora pode ver um deles é superior e o outro é inferior. Para encontrar 162 tive que acrescentar um quadrado. Se a minha resposta estiver errada por favor corrija me por que não entendi muito bem sua pergunta.

Professora F: Oi aluna A, a tua resposta está certa sim. Eu fiz uma pergunta nova, vou me explicar melhor: se eu quiser formar figuras só com triângulos grandes e pequenos, será que eu consigo em algum momento encontrar uma quantia que dê 2, 12, 22, 32, 42, $52,62,72, \ldots$, ou seja, qualquer quantia que termine em dois? Isso é possível somando triângulos grandes que valem 30 e triângulos pequenos que valem 15 ? by profa $\mathrm{F}$

Aluno A: Professora não tem como formar figuras que terminem em 2, 12, 22, 32, 42, 52, 62, 72,... , por que o valor dos triângulos é de 15 e 30, sendo assim, cada um acaba com 0 e 5. Para fazer acabar com dois teria que adicionar outra figura que não é nem triangulo pequeno nem triangulo grande. Por que não tem como somar $15+15=32 e$ nem $30+30=62$. Consegui responder sua pergunta?

Professora F: Simmmmm era isso mesmo que eu estava perguntando, muito bom!!!!

$$
\text { Extrato } 1 \text { - Atividade figuras valiosas - http://alunoA.pbworks.com }
$$

No extrato 1 temos a atividade "Figuras valiosas" que consistia na apresentação de uma tabela onde eram atribuídos valores a figuras geométricas. Em um dos itens da atividade perguntamos aos alunos se era possível compor um desenho usando apenas triângulos e somando o valor destes triângulos encontrarmos como resultado 162. Como os triângulos pequenos e grandes têm como valor 15 e 30 respectivamente, não seria possível obter esse resultado. A aluna A percebe que não é possível e faz dois desenhos só com triângulos e conclui que para encontrar 162 precisaria de um quadrado no desenho como ele ilustra na terceira imagem. A professora segue questionando o aluno com a intenção de auxiliá-lo a pensar mais sobre o problema e encontrar outros meios de explicar a mesma situação.

Este procedimento de intervenção junto aos alunos faz parte da nossa proposta de não oferecer respostas prontas aos alunos e sim com outras perguntas incentivá-los a pensar e construir seus próprios conceitos.

Um dos nossos propósitos era criar um espaço de total liberdade de expressão das idéias dos estudantes. No extrato 2 podemos perceber esta característica do nosso trabalho pelo modo descontraído e informal em que alunos e professores expõem suas idéias. Propusemos esta atividade aos alunos da seguinte maneira:

(por favor ajude a família a atravessar ao outro lado da ponte.

Note que é noite, então eles precisam ter uma lâmpada.

Cada pessoa atravessa a ponte em uma velocidade diferente: 1 segundo, 3 segundos, 6 segundos, 8 segundos e 12 segundos.

A ponte aguenta somente o peso de duas pessoas de cada vez.

O par de pessoas deve atravessar junto a ponte na velocidade da pessoa mais lenta. A lâmpada funciona por 30 segundos somente.) 
Nossa ideia neste desafio era apresentar algo diferente, divertido, e que não fosse apenas uma reprodução de exercícios realizados em sala de aula para a tela do computador, ou seja, procuramos um desafio que levasse o estudante a interagir com o problema e a descrever o processo de resolução mais do que apresentar apenas a resposta final.

\section{Atividade 3:}

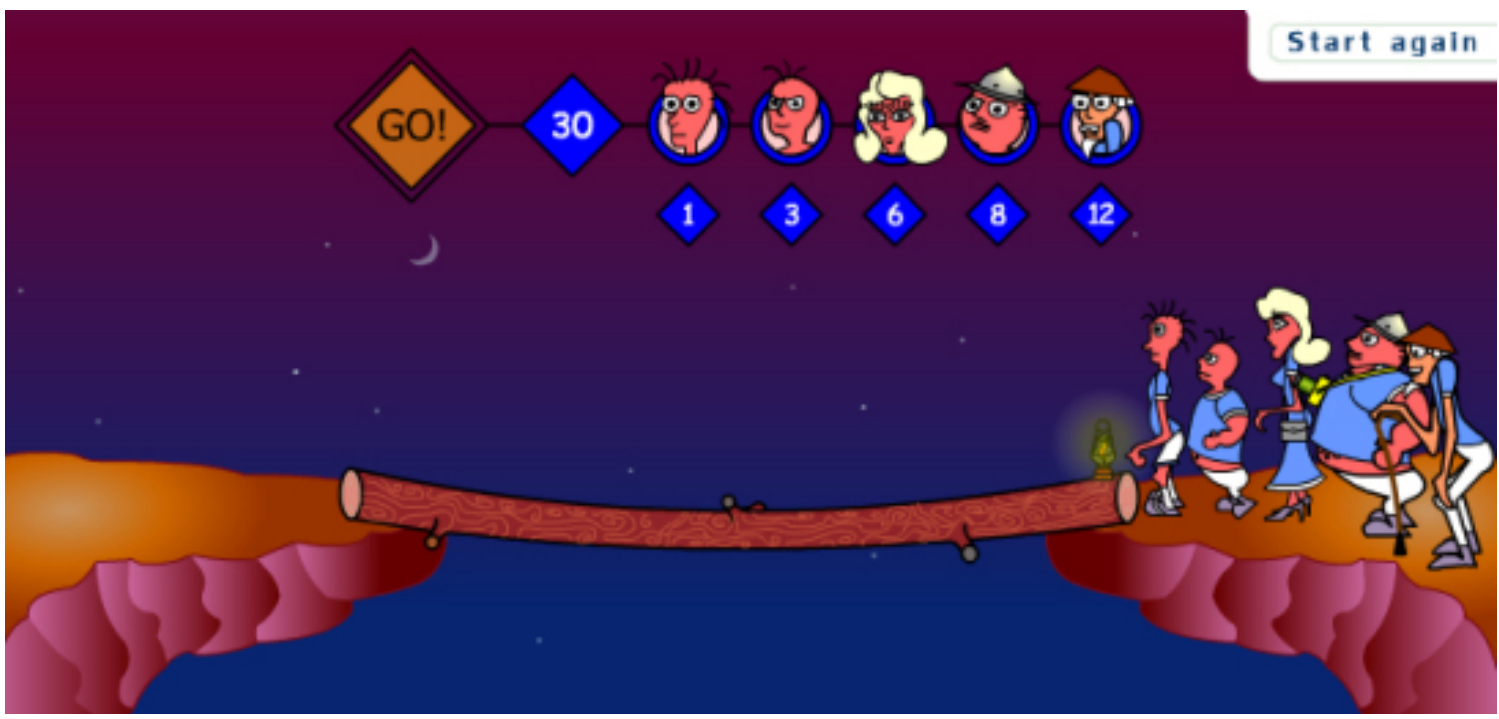

Aluno B: Primeiro, escolhi o que gastava menos tempo para atravessar todos os outros componentes da família, que era o número 1 de tempo. Peguei-o e levei junto para atravessar o número 3, ficou 27 segundo para os restantes, e então, atravessei o número 1 de volta que ficou com 26 segundos para buscar a mulher que gastava 6 segundos, atravessei ela e ficou com 20 segundos, e o trouxe de volta pra buscar o resto, que então ficou com 19 segundos, deixei o número 1, e levei apenas o número 8 e o 12 juntos com a lâmpada, que ficou com apenas 7 segundos, e então peguei o garotinho que gastava 3 segundos e o atravessei para buscar o que gastava apenas 1 segundo, que então ficou com 4 segundos restante, já que os dois juntos gastavam 4 segundos apenas, eu consegui vencer o jogo!

Professora F: Essa tua estratégia me parece matemática, que matemática seria essa?

Aluno B: Não sei dizer bem, apenas somei as quantias diferentes e vi que tinha como dar certo.

Extrato 2 - Atividade figuras valiosas - http://alunoB.pbworks.com

Acreditamos que quando os alunos escrevem sobre suas estratégias de resolução de problemas eles tem a oportunidade de refletir sobre seus raciocínios e de reestruturar o modo como enfrentarão novos problemas. Esta atitude permite o desenvolvimento de autonomia pelos estudantes. 
16.07.09:

1: Qual a relação que as sequências têm com a matemática?

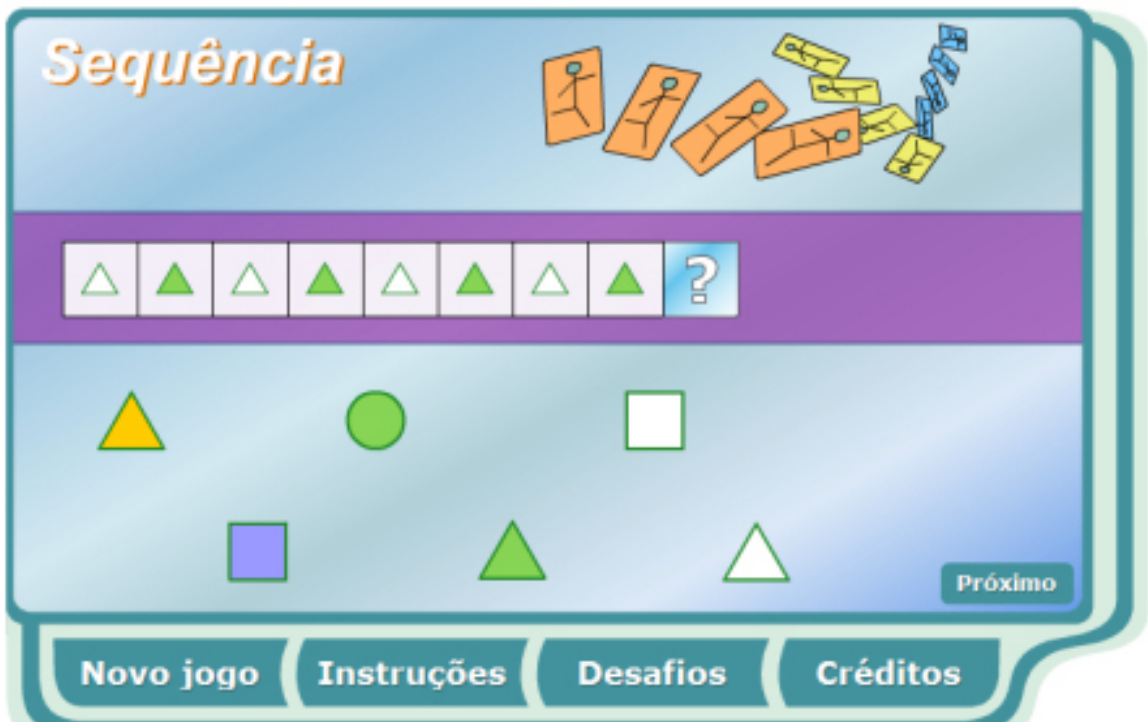

Em matemática, uma sequência, é um conjunto ordenado de objetos, e exemplos de sequências são comuns no nosso dia-a-dia, pois nos deparamos sempre com situações com que enumeramos elementos de um conjunto seguindo uma determinada ordenação.

Professora F: "As sequências são comuns no nosso dia-a-dia", consegues dar alguns exemplos destas sequências?(by profa XXXXXXX - 31/10 - 13:36)

Aluno C: Sim, como numa aula de matemática que nós fazemos sequências de atividades, sejam diferentes ou iguais, ou uma sequência de números, a sequência de água que cai no chuveiro! hehe.

$$
\text { Extrato } 3 \text { - Atividade figuras valiosas - } \underline{\text { htp: }: / / X X X X X X . p b w o r k s . c o m ~}
$$

No extrato 3, destacamos a atividade batalha naval, que pedia que os alunos comparassem o jogo batalha naval ao Plano Cartesiano, conteúdo que estava sendo abordado em sala de aula nesta ocasião.

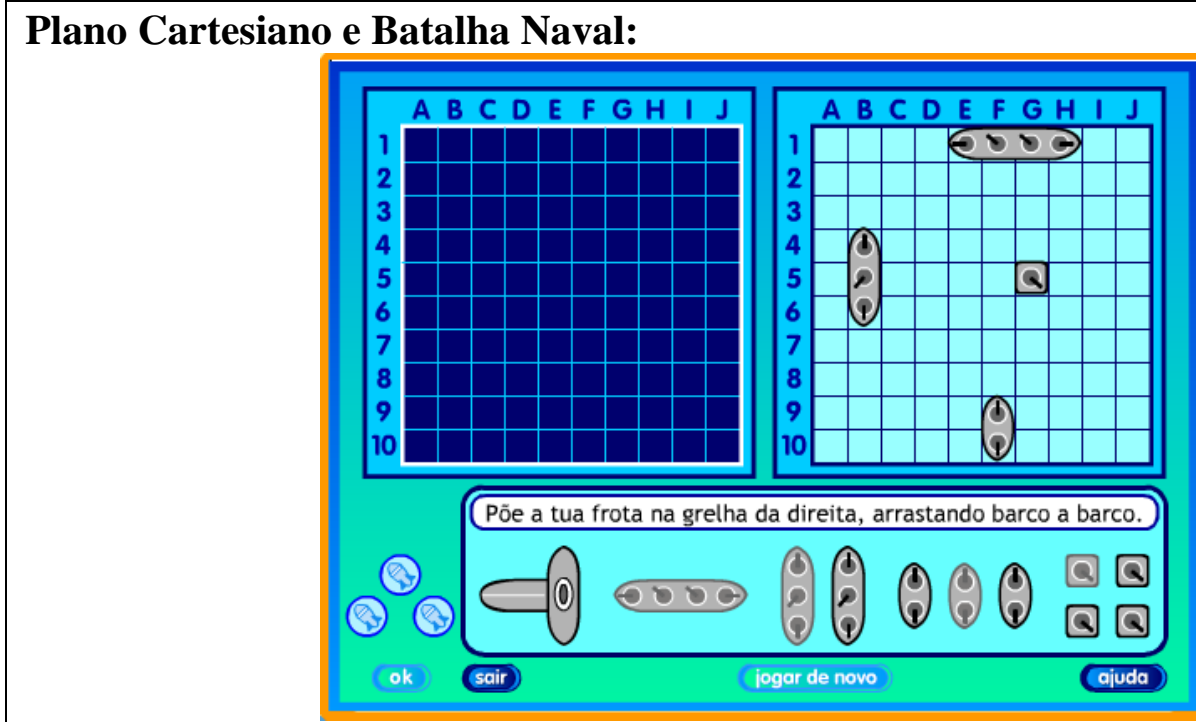


Aluno C: A diferença entre os mesmos são:

No jogo, as semelhanças são que: As retas, são parecidas com o sistema de coordenadas, no caso "o gráfico", que há números para nos orientar. O jogo é contra a máquina e é usado para "brincar", e na sala de aula o sistema cartesiano é usado como um sistema lógico, um estudo.

Professora F: Isso mesmo aluno $\mathrm{C}$, sabia que o sistema cartesiano tem este nome em homenagem ao seu criador, René Descartes? Que tal descobrires o que mais ele contribui na matemática?

Aluno C: Ele foi um filósofo, físico e matemático francês. Notabilizou-se sobretudo por seu trabalho revolucionário na filosofia e na ciência, mas também obteve reconhecimento matemático por sugerir a fusão da álgebra com a geometria - fato que gerou a geometria analítica e o sistema de coordenadas que hoje leva o seu nome. Por fim, ele foi uma das figuras-chave na Revolução Científica.

Extrato 4 - Atividade figuras valiosas - http://alunoC.pbworks.com

No texto destacado acima, a professora $\mathrm{F}$ aproveita a reflexão da aluna para sugerir que aprofunde seu conhecimento sobre o assunto.

No extrato 5 apresentamos um desafio: pedíamos ao aluno que descrevesse as estratégias usadas para jogar tangramz.

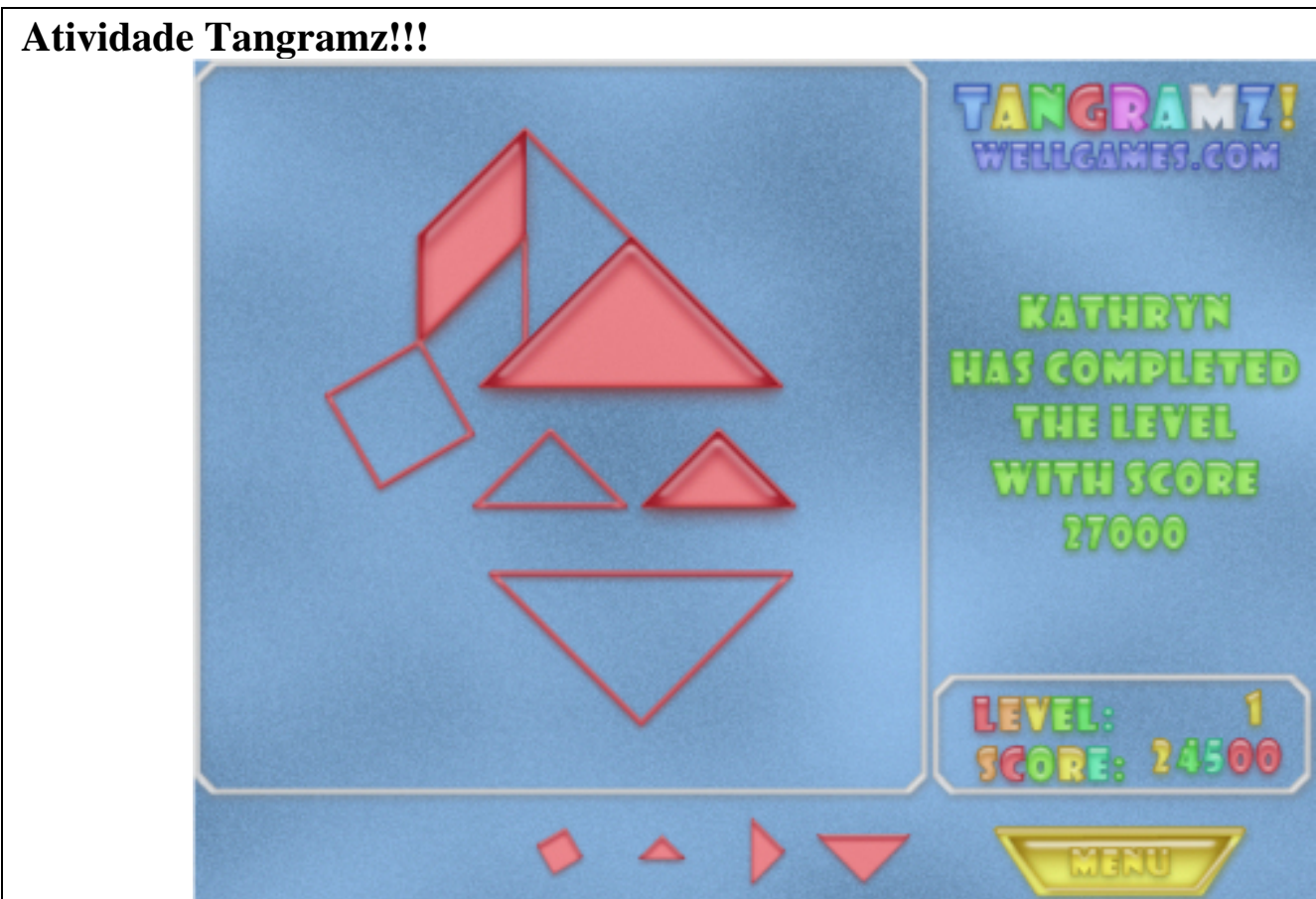

Aluno D: Eu achei beem fácil, eu fui pegando as peças e vendo onde elas se encaixavam aí as que eu não conseguia botar nos espaços sobrando eu desmontava de novo e fazia de novo as vezes tinha que trocar as peças. Nos últimos níveis que joguei encontrei um pouco mais de dificuldade pq eram muitas figuras e eu fiqueei bem confusa. Adoorei ;)

Este jogo é o famoso jogo de origens Chinesas, o tangram (Já ouvi falar nisso antes...). Formado por sete peças, o tangram era, e é até hoje, usado como método de raciocínio, ajuda na memória e também nos reflexos. O objetivo do jogo é 
procurar construir uma figura apartir de sete partes de um quadrado (Pelo menos foi o que aprendi=D)

(http://www.ojogos.com.br/jogo/Tangrams.html)

\section{Comentário do aluno D:}

Que legal este jogo!! Gostei bastante (E não estou puxando saco de ninguém, viu?? $=P)$

Eu já tinha jogado este jogo na 4 série... e tinha gostado também...

Só não entendi uma coisinha... Por que o trangram é usado na matemática??

\section{Comentário da Professora F:}

Oi aluno D, to gostando de ver, olha só, o Tangran tem muito a ver com matemática, podemos trabalhar a visualização e representação de figuras plana, exploração de transformações geométricas através de decomposição e composição de figuras, compreensão das propriedades das figuras geométricas planas,noções de áreas, frações, ângulos, hi Ana acho qté que tem mais coisas ainda. Que tu achas?Tu descobre mais uma? pensa ai!!!

(by profa F - 02/05/2009 - 19:39)

Professora F: Oi voltei, eu fiquei pensando e olha só, o Tangram é um quebra-cabeça chinês, que surgiu a muito tempo atrás. Tangran quer dizer as sete tábuas da sabedoria. Ele é formado por sete peças. 5 triângulos de diferentes tamanhos, 1 quadrado e um paralelogramo. Todas estas formas geométricas surgem da decomposição de um quadrado, ou seja, se pegarmos um quadrado de papel e uma tesoura, e recortarmos algumas partes, chegamos nestas figuras. Só com as 7 peças do tangran conseguimos montar mais de 1500 figuras.

Pergunta: Tu consegues me explicar como a partir de um quadrado de papel e uma tesoura, tu chegas a 1 triângulo? e a partir de outro quadrado de papel tu chegas a um paralelogramo? Vale desenho, imagens da internet e o que mais tu quiseres usar ok? Só não te esquece de colocar junto a imagem a referência, ou seja, de qual site tu pegou o material ok?

(by profa F- 02/05/2009 - 21:03)

Aluno D: ..não endendi tua pergunta, sora! Pode me explicar melhor??

Professora F: Claro, olha só: tu tens um quadrado de papel na mão ok? daí tu pega uma tesoura e recorta uma ou mais partes para virar um triângulo. O que eu quero é que tu me descreva como tu faz isso, que parte tu corta, entendeu?

E daí o mesmo para um paralelogramo.(by profa F - 03/05/2009 - 15:55)

Resposta da Pergunta:

Aluno E: Acho que eu entendi... Eu dobraria o quadrado ao meio e recortaria a parte do meioe um paralelogramo, eu recortaria um triangulo pequeno em dois lados do quadrado!

Extrato 5 - Atividade figuras valiosas - http://alunoD.pbworks.com

A aluna descreve sua estratégia, expõe seus limites no jogo e fala um pouco do que sabe sobre tangram. Do modo como desenvolvemos este trabalho, sempre questionando os alunos a cerca dos seus pensamentos, mas de modo descontraído e informal permite que os alunos sintam-se a vontade para elaborar questões como esta da aluna D: “Só não entendi uma coisinha... Por que o trangram é usado na matemática??”. 
Segundo Moore (apud Peters, 2001), a distância transacional é máxima quando estudantes e docentes não tem qualquer intercomunicação e quando o programa de ensino está pré-programado em todos os detalhes sem que necessidades individuais sejam respeitadas e analogamente ela é mínima se o programa de estudos não é fixo, enseja freqüentes diálogos, nos quais podem expressar-se os pré-conhecimentos, interesses e desejos dos estudantes individualmente, determinando o andamento do ensinar e aprender.

Podemos perceber este diálogo e esta estrutura flexível nos extratos destacados acima bem como nos pbworks não citados no presente artigo. Os alunos participaram ativamente da construção deste ensino-aprendizagem. Entendemos que esta comunicação diminui a distância entre professor-aluno e também minimiza o tempo que o aluno leva para obter auxílio.

Além dos pbworks, também usamos e-mail e MSN. Abaixo destaco um extrato de uma conversa entre professor e aluno, o primeiro, via e-mail, e o segundo, via MSN:

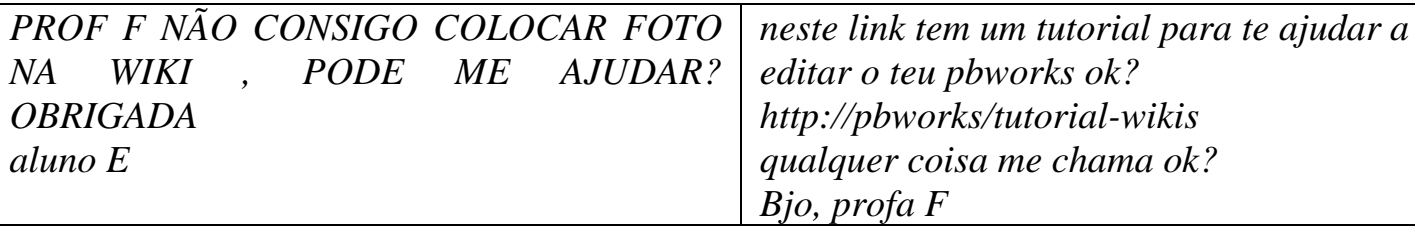

No extrato acima a aluna pede ajuda para fazer upload das imagens para continuar a construção do seu pbworks e a professora F indica para ela um tutorial construído para auxiliar os estudantes a editarem seus wikis. $\mathrm{O}$ aluno E recebe auxílio para prosseguir a atividade sem precisar esperar até o próximo encontro presencial. Esta prática de ensino/aprendizagem é então também uma relação à estruturação do material e os diálogos que ocorre entre professor e aluno. Quanto menos flexível for a estrutura oferecida pelo professor, menor será o envolvimento do aluno, ou seja, maior será a distância transacional.

Já no extrato abaixo vemos um diálogo da professora $\mathrm{F}$ com um aluno, a atividade dele era refazer as questões da prova que não estavam corretas:

\begin{tabular}{|c|c|}
\hline $\begin{array}{l}\text { Aluno F diz (20:08): } \\
* 5 x-20^{\circ}=2 x+70\end{array}$ & $\begin{array}{l}\text { Aluno F diz (20:31): } \\
\text { *devo }\end{array}$ \\
\hline Aluno F diz (20:09): & Sora F diz (20:32): \\
\hline$* 5 x-2 x=$ & *isso então qual é o resultado \\
\hline *dai da pra bota $70+20$ oи $20+70 ?$ & Aluno F diz (20:32): \\
\hline *não faz diferença né & *6 \\
\hline *? & sora F diz (20:33): \\
\hline sora F diz (20:09): & *tem certeza \\
\hline *é a mesma coisa & *tu não me disse que tu deve seis? \\
\hline *se a gente faz $70+20$ da 90 & Aluno F diz (20:33): \\
\hline sora F diz (20:29): & sora F diz (20:33): \\
\hline *olha só & *então como se escreve "em matemática" \\
\hline sora F diz (20:30): & devo 6 \\
\hline $\begin{array}{l}\text { *tu deve } 5 \text { e tem } 11 \text { dá pra ter } 16 \text { no } \\
\text { final? }\end{array}$ & $\begin{array}{l}\text { Aluno F diz (20:33): } \\
*_{-6}\end{array}$ \\
\hline $\begin{array}{l}\text { Aluno F diz (20:31): } \\
\text { *não dá } 6\end{array}$ & $\begin{array}{l}\text { sora F diz (20:34): } \\
*_{i s s o}\end{array}$ \\
\hline
\end{tabular}




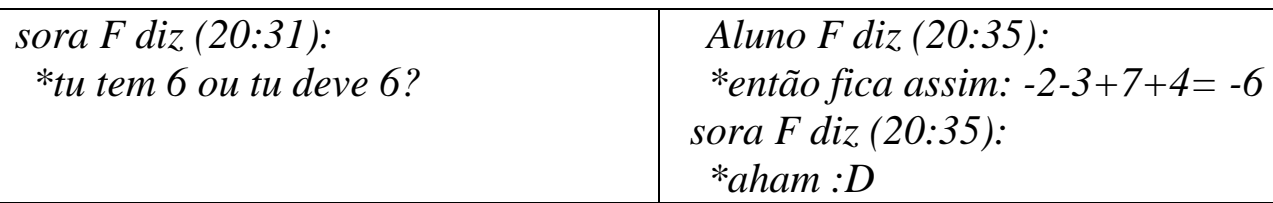

Refletindo a proposta do nosso trabalho a professora $\mathrm{F}$ vai questionando o estudante para que ele chegue à resposta sem oferecer uma resposta imediata.

\section{Conclusões e Perspectivas}

A característica das atividades escolhidas de não permitirem uma resposta única e exigir que os estudantes descrevessem os procedimentos de resolução dos desafios, permitiu que eles refletissem sobre os seus próprios raciocínios matemáticos. Uma vez que o estudante pense sobre seu próprio raciocínio ele tem a possibilidade de reelaborálo, e esta prática contínua leva o aluno a aprender a aprender.

A possibilidade de contato extra-classe entre aluno e professor, permitiu uma aproximação entre estes de modo que alguns alunos mais tímidos, encontraram um canal de comunicação onde eram ouvidos e assim, revelando ao professor suas dúvidas e suas certezas.

O trabalho de construção do seu próprio aprender nos seus pbworks permitiu aos alunos desenvolverem autonomia e a capacidade de buscar soluções aos problemas apresentados.

Devido à riqueza de possibilidades desta proposta, além de pretendermos dar prosseguimento à sua implementação com alunos das demais turmas do Ensino Fundamental e Médio do CAp-UFRGS, com características também interdisciplinares, envolvendo as áreas de física, química, biologia, educação física, inglês e outras, é intenção prosseguirmos o trabalho de investigação, movidos por novas interrogações surgidas durante a atual pesquisa.

1 - Como os alunos trabalham cooperativamente usando os pbwikis?

2 - Quais são os limites e quais são os benefícios desta proposta para o fazer pedagógico do professor e para a aprendizagem dos estudantes?

3 - Quais são as diferenças dos conceitos de aprender e ensinar no trabalho com os pbwikis em relação ao trabalho em sala de aula?

4 - Como os alunos constroem os conceitos e as atitudes nesta proposta que mescla a modalidade presencial e a distância?

No atual estágio desta investigação, com base nos dados obtidos, concluímos que a proposta apresentada se mostrou favorável a apropriação de novos conceitos, capacidades e atitudes por parte dos alunos, contribuindo, portanto, para a aprendizagem de matemática.

Também foi possível constatar que esse trabalho tem um impacto sobre o trabalho dos docentes na medida em que os processos de interação estabelecidos entre esses e seus alunos foi potencializado pelos usos dos recursos digitais de comunicação na modalidade ora apresentada.

\section{Referências}

VEEN, Wim; VRAKKING, Bem. Homo Zappiens: Educando na Era Digital. Porto Alegre: Artmed, 2009.

PAPERT, Seymour. A Máquina das Crianças: repensando a escola na era da informática. Porto Alegre: Artmed, 2008. 
PETERS, Otto. Didática do Ensino a Distância. São Leopoldo: Editora Unisinos, 2001. 